\title{
Intact parasite-antigen ELISA test: a new dimension for serodiagnosis of Amoebiasis
}

\begin{abstract}
Archana Mishra
Department of Zoology, University of Lucknow, Lucknow- 226007 (U. P.), India Ajay Kumar Sharma*

Department of Zoology, University of Lucknow, Lucknow- 226007 (U. P.), India Vandana Tewari

Department of Biochemistry, Dr. Ram Manohar Lohia Institute of Medical Sciences, Vibhuti Khand, Gomti Nagar Lucknow 226010 (U.P.), India

*Corresponding author. E-mail: draksharma57@gmail.com

Abstract

An Intact Parasite Antigen ELISA (IPA-ELISA) has been developed for detection of circulating antibodies against Entamoeba. histolytica. Axenically grown trophozoites of E.histolytica (NIH-200) after glutaraldehyde treatment, are used as Intact Parasite Antigen (IPA) as well biological active and imperishable base. Antigen over the surface of treated cells were allowed to interact with the antibody molecules of the test sera. The techniques of Plate, Dot-and IPA-ELISA are compared of their merits for clinical and epidemiological survey of amoebiasis. IPA-ELISA was found to be more sensitive (96.8\%) and specific $(92.3 \%)$ in detecting circulating antibodies compared to Plate-ELISA (sensitivity $90.5 \%$, specificity $84.6 \%$ ) and Do-ELISA (sensitivity $92.1 \%$, specificity $86.1 \%$ ). The entire IPA-ELISA test could be completed within 3 hours. Costwise IPA-ELISA is several times lesser than Dot-and Plate-ELISA. This test is most suitable for field and clinical trials for suspected cases of amoebiasis with no skilled hand required for diagnosis.
\end{abstract}

Keywords: Amoebiasis, Amoebic liver abscess, Entamoeba histolytica, IPA-ELISA

\section{Article Info}

DOI:10.31018/jans.v10i3.1835

Received: July 21,2018

Revised: August 4, 2018

Accepted: August 8, 2018

\section{How to Cite}

Mishra, A. et al. (2018).

Intact parasite-antigen

ELISA test: a new dimension for serodiagnosis of Amoebiasis. Journal of Applied and Natural Science, 10(3): 976 - 980

\section{INTRODUCTION}

Human infection, caused by the intestinal protozoan parasite Entamoeba histolytica occurs worldwide, especially in the population of developing countries in Aisa, Africa and Latin America. Amebiasis is a chief reason of morbidity and mortality worldwide, frequently in tropical and sub-tropical countries characterized by insufficient health services and sanitation infrastructure (Fotedar et al., 2007). A majority of infected individuals (90\%) are asymptomatic carriers of the parasite. The majority of deaths are a consequence of severe complications associated with intestinal or extraintestinal invasive disease (Ayed and Sabbahi , 2007). Approximately 50,000 to $1,00,000$ deaths are caused by untreated amoebic infection (Walsh, 1986) annually emphasizing the need for reliable tools in the diagnosis of invasive amoebiasis. Invasive amoebiasis is usually diagnosed on the basis of clinical symptoms and ultrasound or radiological examination. However, these methods cannot differentiate between abscess caused by $E$. histolytica or by pyogenic demonstration of cyst/trophozoties in stool specimens. However, this technique is not suitable for large-scale epidemiological survey.

On the other hand, detection of circulating amoebic antibodies in patients is a more reliable method of diagnosing extra intestinal amoebiasis, since invasive amoebic infection provoke a strong humoral response especially of immunoglobulin-G (IgG) isotype (Trissl, 1982, Knappik et al., 2005). A number of immunodiagnostic techniques have been described for both intestinal and extraintestinal amoebiasis with variable degree of sensitivity and specificity. Plate ELISA is successfully applied to the serodiagnosis of amoebiasis. (Rosenblatt et al., 1995, Punthuprapasa et al., 2001, Haghighi et al., 2005) Dot ELISA for serodiagnosis of amoebiasis is also reported (Mahajan et al., 1989: Lopez et al., 1991, Yamura et al., 2003, Van Doorn et al., 2005, Dhanalakshmi et al., 2016). The present study was undertaken to develop Intact Parasite Antigen-ELISA (IPAELISA)test in the diagnosis of intestinal and extraintestinal amoebiasis and also to determine its sensitivity and specificity in comparision to PlateELISA, Dot Elisa.The relative merits of tests were also found out for clinical and epidemiological sur- 
vey of amoebiasis.

\section{MATERIALS AND METHODS}

Preparation of antigen of E.histolytica: Trophozoites $\left(5-6 \times 10^{8} / \mathrm{ml}\right)$ of axenic strain of E. histolytica (NIH-200), maintained in TYI-S-33 medium of Diamond (1978), were sonicated and centrifuged. Crude antigen was subjected to preparative polyacrylamide gel electrophoresis (Laemelli, 1970). Bands of antigen, detected by the standard method of Towbin et at. (1979) were extracted from gel by submarine electrophoresis (Leppard et al., 1983).

Raising of Hyper immune serum (HIS): Antibodies against the purified antigen $(80-100 \mathrm{kDa})$, raised in albino rabbit $(1.5-2 \mathrm{~kg})$. Two doses of $1-2$ $\times 10^{6}$ trophozoites in $1 \mathrm{ml}$ Phosphate Buffer saline (PBS) emulsified with $1 \mathrm{ml}$ of Complete Freund's Adjuvant (CFA) were administered subcutaneously. Another two doses with Incomplete Freund's Adjuvant (IFA) and last dose without adjuvant. Following one week of last injection, rabbits were bled and serum collected.

Stabilization of trophozoite with glutaraldehyde: Standard method of Fierros et al.,(1996) was followed. In brief, 5-6 $\times 10^{7}$ trophozoites of $E$. histolytica were suspended in $5 \mathrm{ml}$ glutaraldehyde salt solution [composition: $\mathrm{Na}_{2} \mathrm{HPO}_{4}(0.15$ M) $6.4 \mathrm{ml}, \mathrm{NaCl}(0.15 \mathrm{M}) 57.6 \mathrm{ml}$, distilled water $0.32 \mathrm{ml}$, glutaraldehyde aqueous solution $(25 \% \mathrm{v} /$ v) $4 \mathrm{ml}$ ] Contents were gently rotated and stored at $4^{\circ} \mathrm{C}$ for $30 \mathrm{~min}$. Glutaraldehyde was removed by exhaustive washing $(5 \mathrm{x})$ with $0.15 \mathrm{M} \mathrm{NaCl}$ and subsequently 5 times with distilled water.

Collection of clinical serum samples: The serum samplels $(n=63)$ were obtained from KGMU, Lucknow with clinically proven amoebiasis as diagnosed by the history of pain in the right hypocardium, enlarged tender liver, fever, ultrasound investigation, absence of bacteria in aspirated pus and presence of cysts in stool. Sera used as negative controls $(n=15)$ included those obtained from healthy individuals, confirmed by microscopy and culture on three consecutive day examinations and patients with giardiasis, leishmaniasis, filariasis, malaria and tuberculosis $(n=10$ samples each). All sera were divided into aliquots and stored at $20^{\circ} \mathrm{C}$.

ELISA-Techniques: Plate-ELISA was performed by standard method of Engvall and Perlmann (1971), Dot-ELISA by Baveja el al., (1991) to detect the antibodiies in clinical serum samples.

Intact Parasite-Antigen ELISA (IPA-ELISA): Exponentially growing trophozoites of $E$. histolyti$\mathrm{ca}$ in TYI-S-33 medium were harvested. An equal volume of $0.25 \%$ glutaraldehyde in PBS was dispensed and contents mixed thoroughly. After 1 hour at room temperature, trophozoites were washed three times in PBS (pH 7.2) for 10 minutes each and counted in haemocytometer and adjusted to a proper density of $1 \times 10^{3}$ cells/ $\mathrm{ml}$ in PBS. An aliquots of $30 \mathrm{ml}$ carrying 30-40 trphozoites was dispensed over a teflon coated multispot glass slide (Wellcome Diagnostic, U.K.). The smear was allowed to dry at room temperature, fixed in chillled acetone for $\mathbf{2 0} \mathrm{min}$ and stored at $-20^{\circ} \mathrm{C}$ until used.

To perform the IPA-ELISA, an aliquot of $30 \mathrm{ml}$ of serum in a suitable dilution (ranging between 1:50 TO 1:6400) was dispensed over the parasite smear and incubated at $37^{\circ} \mathrm{C}$ for $1 \mathrm{~h}$. Slides were thoroughly washed with PBS and treated with 30 $\mathrm{ml}$ of anti-human IgG (g-chain specific) -HRP conjugate at a dilution of $1: 1000$ for $1 \mathrm{~h}$ at $37^{\circ} \mathrm{C}$ in a humid chamber. Smears were gently washed with PBS-Tween 20 (PBS-T) treated for $30 \mathrm{~min}$ at $37^{\circ} \mathrm{C}$ with $30 \mathrm{ml}$ of freshly prepared 3,3' diaminebenzidine (DAB) substrate solution [6 $\mathrm{mg}$ in $10 \mathrm{ml}$ PBS $+30 \mathrm{Im} \mathrm{H}_{2} \mathrm{O}_{2}(30 \% \mathrm{v} / \mathrm{v})$ slides were further washed with PBS and examined under light microscope. Development of dark brown colour in trophozoites, prominently on surface, was considered as positive (Fig.1).

\section{RESULTS}

Plate-ELISA: Sera from positive cases yielded intense orange colour in flat bottom wells of polystyrene plate. The optical density was read by ELISA-reader. The cutoff value ( $2 \mathrm{SD}+\mathrm{OD})$ of the test was set at 0.287 . Above this OD value all samples were considered as positive. Forty-eight out of fifty-three sera of Amoebic Dysentry (AD) and 9 out of 10 cases of Amoebic Liver Abscess (ALA) showed positive reaction. Two out of ten cases of malaria and three out of ten sera samples of tuberculosis showed positive reaction. The sera samples of leishmaniasis and filariasis turned negative. Sensitivity and specificity of the test turned $90.5 \%$ and $84.6 \%$ respectively.

Dot-ELISA: Positive sera yielded intense brown colour spot on pale yellow background of nitrocellulose paper (NCP). Forty-nine out of 53 sera of $A D$ and 9 out of 10 ALA cases showed positive reaction. However 3 out of 10 cases of giardiasis, 3 out of ten cases of tuberculosis and 2 out of 10 cases of malaria gave positive reaction. Ten sera samples each of leishmaniasis and filariasis turned negative. Sensitivity and specificity of test was $92.06 \%$ and $86.1 \%$ respectively.

IPA-ELISA: Development of dark brown colour in trophozoites prominently on surface was considered as positive result, however no such colour appeared with negative samples [Fig. 1(a) and Fig. 1 (b)]. Fifty-one out of 53 of $A D$ and all ten sera samples of ALA gave positive reaction by IPA-ELISA in titre ranging 1:200 to $1: 1600$. The cutoff value of test sera was set at 1:100. Normally samples below the cutoff value were termed negative debarring a few exceptional cases. Two out of ten of giardiasis and two out of ten sera 
Mishra, A. et al. / J. Appl. \& Nat. Sci. 10 (3): 976 - 980 (2018)

Table 1. Qualitative evaluation of tests for the diagnosis of invasive amoebiasis

\begin{tabular}{|c|c|c|c|c|}
\hline & & Plate- ELISA & Dot- ELISA & IPA- ELISA \\
\hline Sensitivity & {$[A /(A+C)] \times 100$} & 90.50 & 92.45 & 96.82 \\
\hline Specificity & {$[\mathrm{D} /(\mathrm{B}+\mathrm{D})] \times 100$} & 84.60 & 86.10 & 92.30 \\
\hline Positive & {$[A /(A+B)] \times 100$} & 85.07 & 85.29 & 92.42 \\
\hline $\begin{array}{l}\text { Predictive Value } \\
\text { Negative } \\
\text { Predictive Value }\end{array}$ & {$[D /(C+D)] \times 100$} & 90.16 & 91.67 & 96.77 \\
\hline False Positive & {$[\mathrm{B} /(\mathrm{B}+\mathrm{D})] \times 100$} & 15.38 & 15.38 & 07.69 \\
\hline False Negative & {$[\mathrm{C} /(\mathrm{C}+\mathrm{D})] \times 100$} & 09.80 & 08.30 & 03.22 \\
\hline
\end{tabular}

*Values expressed as percentage. $A=C$ Cinically positive + test positive; $B=C$ linically Negative + test positive; $C=$ Clinically positive + test Negative; $D=$ Clinically Negative + test Negative.

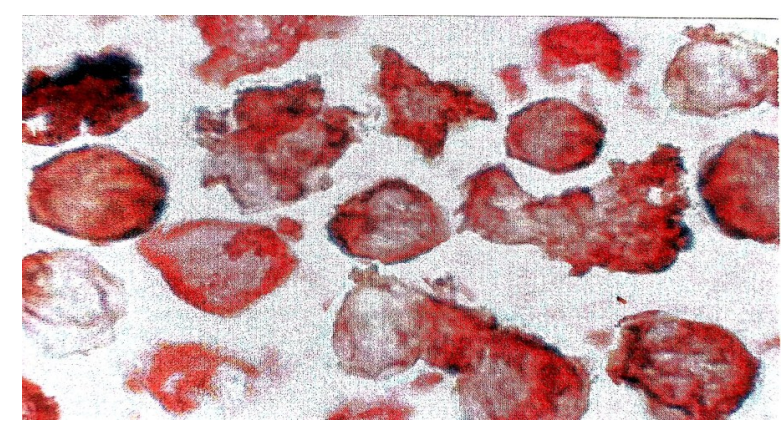

Fig.1. (A) IPA ELISA TEST: Positive Control.

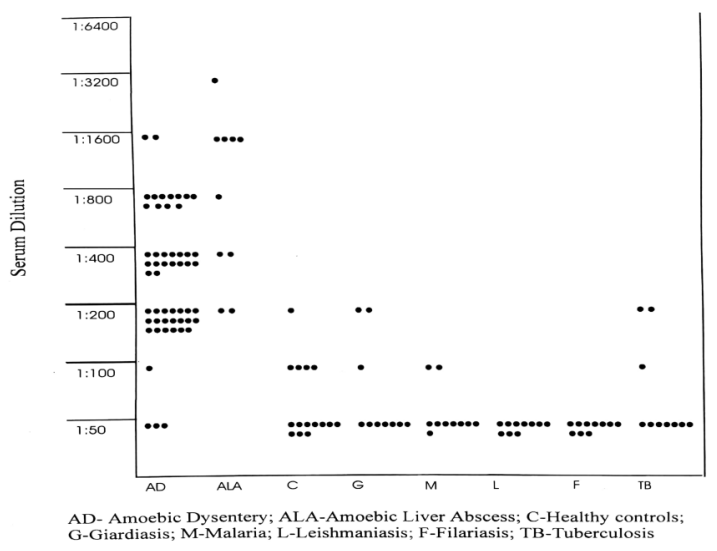

Fig.2.IPA ELISA test for Amoebiasis.

sample of tuberculosis were positive at dilution $1: 200$. All the sera sample of filariasis, malaria and leishmaniasis turned negative (Fig.2). Sensitivity of IPA-ELISA was $96.8 \%$ and specificity was $92.3 \%$. Negative and positive predictive values were $96.7 \%$ and $92.4 \%$ and false negativity and false positivity values as 3.22 and $7.69 \%$ respectively. Corresponding values of Plate-ELISA and Dot-ELISA are cited in table 1.

Stability of antigen for IPA-ELISA test: The stability of antigen was tested upon storage at room temperature of $30^{\circ} \mathrm{C}, 4^{\circ} \mathrm{C}$ and $-20^{\circ} \mathrm{C}$ for not more than ten months. Test was carried out from same batch of antigen with same serum sample at the same dilution. Storage at $4^{\circ} \mathrm{C}$ and $20^{\circ} \mathrm{C}$ gave satisfactory results for a long period of time i.e. 7 months and 9 months respectively while antigen was unstable at room temperature beyond 4 days (Fig.3).

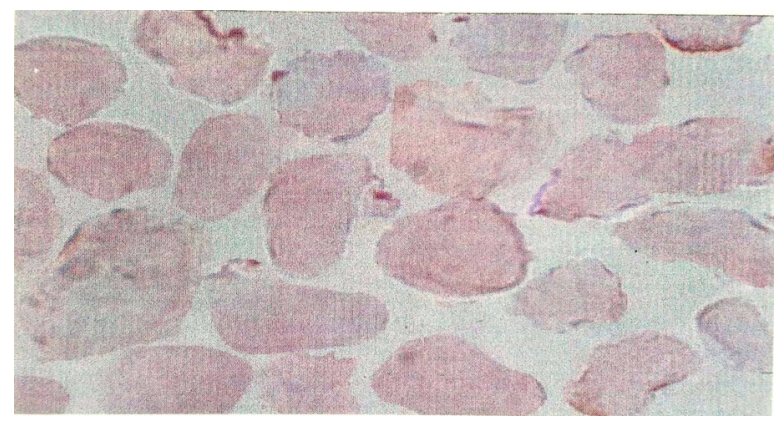

Fig.1. (B). IPA ELISA TEST: Negative Control.

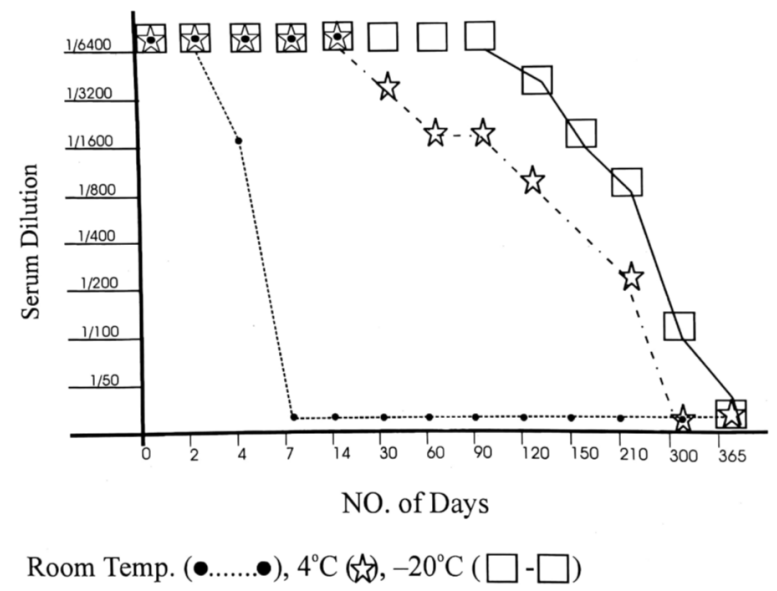

Fig.3.Shelf life of antigen for IPA ELISA test.

\section{DISCUSSION}

Entamoeba histolytica is one of the most frequent parasitic infections globally, infecting about 50 million people and resulting in 40 000-100 000 mortality a year (Van et al.,2007 ). Diagnosis of amoebiasis is usually made by the observation of cyst/ trophozoites of E._histolytica in stool samples. However, microscopy technique is not preferred for wide spread epidemiological survey. Extraintestinal amoebiasis, especially the hepatic amoebiasis, cannot be diagnosed by stool examination as the parasite does not show-up in test smears. Serodiagnosis of amoebiasis offers a great promise for dependable diagnosis of amoebic infection. A simple immuno-diagnostic test with high sensitivity and specificity would carry an added advantage (Leo et al.,2006) .

Unlike Plate ELISA, which required a large volume 
of antigen, Dot-ELISA required only $2 \mathrm{ml}$ of sample per dot, on NCP. Sample coated strips could be stored after blocking the untreated sites for over 6 months in a solution of sucrose containing sodium azide or in dry state at room temperature upto $37^{\circ} \mathrm{C}$ for 15 weeks, if packed suitably (Kumar et al., 1985). The results could be recorded with naked eyes without the use of sophisticated instrument, hence it is well suited for field trials. Cost wise IPA-ELISA worked out to be most economic because it does not require any specific and sophisticated instrument to read interpret the test results. Relatively IPA-ELISA appeared to be of added advantage over the Dot and PlateELISA. In principle all the three techniques are alike, in the serodiagnosis of amoebiasis. Wong et al. (2017) also have done similar type of work using crude soluble antigen of E. histolytica. However, the special features of the IPA-ELISA, lies in employing whole parasite as antigen for the test. Treatment of $E$. histolytica trophozoites with glutaraldehyde, provided a prolonged shelf life to the cells. Moreover, as reported earlier (Fierros et al., 1996) glutaraldehyde did not cause any damage to the cell or the antigen, therefore performance of the test was not adversely affected. Glutaraldehyde treatment offered a biologically active and imperishable base over which the surface antigens were maintained effective to interact with the antibody molecules of the test serum.

It is also convenient to carry the test reagents from place to place during field trials. Keeping this in view, the IPA-ELISA appeared as the best out of the three tests investigated in the present study, as it helped to detect $100 \%$ ALA cases while Plate and Dot-ELISA showed positivity of $90 \%$. Brown shaded trophozoites even $5-10$ in number could be located under light microscope at high magnification. This reduced the required amount of antibody molecules to nano or picogram. This explains the sensitivity and specificity of the test. IPA-ELISA may therefore be recommended as a quantitative diagnostic test, since it is rapid, cost effective, sensitive and easy to perform in clinical or field trials.

Microscopy is not suitable for extra intestinal amoebiasis (invasive amoebiasis). Serological tests are more reliable methods of diagnosing invasive amoebiasis. These tests with high sensitivity and specificity would carry an advantage. In this study we have compared Intact Parasitic ELISA (IPAELISA) with Plate ELISA, Dot ELISA.

In this study we have found that IPA ELISA may be recommended because it is rapid, effective, sensitive and easy to perform in clinical and field trials.

\section{Conclusion}

Microscopy is not suitable for extra intestinal amoebiasis (invasive amoebiasis). Serodiagnostic tests are more reliable methods of diagnosing invasive amoebiasis. These tests are with high sensitivity and specificity and would carry an advantage. In this study, we have developed Intact Parasite Antigen ELISA (IPA ELISA) test and compared it with Plate ELISA, DOT ELISA. IPA ELISA may be recommended for the diagnosis invasive amoebiasis because it is rapid, effective, sensitive and easy to perform in clinical and field trials

\section{ACKNOWLEDGEMENTS}

One of the author Dr.Archana Mishra thanks to the Council of Science and Technology, U.P. (India) for financial assistance. We are grateful to the Director, Central Drug Research Institute, Lucknow for the encouragement and support provided during this work.

\section{REFERENCES}

1. Ayed, L. B., Alouini, Z., Jemli, M., \& Sabbahi, S. (2007). Evaluation of the parasite prevalence of sewage and sludge samples in Tunisia. Environnement, Risques \& Santé, 6(6), 433-442.

2. Baveja U.K., Roy T., Kkaur M., Kulpati D.D.S., Agarwal S.k. (1991)- Dot immunobinding assay versus sandwitch ELISA in diagnosis of invasive amoebiasis. Ind. J. Med. Res., 93(A), 161-165.

3. Dhanalakshmi, S., and Parija, S. C. (2016). Seroprevalence of Entamoeba histolytica from a tertiary care hospital, South India. Tropical Parasitology, 6 (1), 78.

4. Diamond L.S., Harlow D.R.and-Cunnick C.C. (1978)A new medium for the axenic cultivation of Entamoeba histolytica and other Entamoeba. Trans. R. Soc. Trop. Med. Hyg., 72, 431-432.

5. Engvall E., Perlmann P. (1971)-Enzyme linkedsorbent assay (ELISA): Quantitative assay of immunoglobulin-G. Immunochemistry, $\underline{\mathbf{8}}$, 871-873.

6. Fierros L.M., Robles M.C.D., Rincon F.E. (1996). Immunodominant Entamoeba histolytica antigen recognized by serum and intestinal antibodies after local or systemic immunization of mice with glutadehyde fixed trophozoites. Life Science, 59, 1283-1295.

7. Fotedar, R, Stark, D, Beebe, N, Marriott, D, Ellis, J and Harkness, J (2007). Laboratory diagnostic techniques for Entamoeba species. Clin Microbiol Rev. 20, pp. 511-532.

8. Haghighi A., Rezaeian M. (2005)-Dectection of serum antibody to Entamoeba histolytica in various population samples of amebic infection using an enzyme linked immunosorbent assay. Parasitol. Res., 97(3), 209-212.

9. Knappik, M., Börner, U., \& Jelinek, T. (2005). Sensitivity and specificity of a new commercial enzymelinked immunoassay kit for detecting Entamoeba histolytica IgG antibodies in serum samples. European Journal of Clinical Microbiology and Infectious Diseases, 24(10), 701-703.

10.Laemelli U.K. (1970)-Cleavage of structural proteins during the assembly of the head of bacteriophage $T_{4}$. Nature, 277, 680-685.

11.Leo, M., Haque, R., Kabir, M., Roy, S., Lahlou, R. M., Mondal, D., and Petri, W. A. (2006). Evaluation of Entamoeba histolytica antigen and antibody point-of- 
care tests for the rapid diagnosis of amebiasis. Journal of clinical microbiology, 44(12), 4569-4571.

12.Leppard K.N., Totty M., Waterfield E., Harlow J., Jenkins Crawford (1983)-Purification and partial amino acid sequence analysis of the cellular tumour antigen p53 from mouse SV 40 transformed cell. EMBOJ, 2, 1993-1999.

13.Lopez R.R., Navarro G.F., Valadez-sanchez M., Lopez V.Y., Calva M. J. (1991)-Dot-Enzyme linked immunosorbent assay (Dot-ELISA) of anti Entamoeba histolytica antibodies in human serum and colostrum. Arch Invest. Med. (Mex), 22 (3-4), 249-253.

14.Mahajan R.C., Sehgal S., Malla N., Ganguly N.K. (1989)-Dot Enzyme linked immunosorbent assay for immuno-diagnosis of ameobiasis. Ind. J.Med.Red., 89, 100-104.

15.Punthuprapasa P., Thammapalerd N., Chularerk U., Charoenlarp K., Bhaibulaya M. (2001)-Diagnosis of intestinal amoebiasis using salivary $\lg A$ antibody detection. Southeast Asian J. Trop. Med. Public Health, 32 (Suppl.) (2) 159-164.

16.Rosenblatt J.E., Sloan L.M., Bestrom J.E. (1995)Evaluation of an enzyme linked immunoassay for the detection in serum of antibodies to Entamoeba histoIytica. Diag. Microbiol. and Infec. Dis. 22(3):275-278.

17. Towbin H., Staehelin, T. Gordon (1979)Elecrophoretic transfer of protein from polyacryla- mide gels to nitrocellulose sheets. Proc. Nat. Acad. Sci. USA, 76, 4350-4354.

18.TrissI D. (1982)-Immunology of Entamoeba histolytica in human and animal hosts. Rev. Infec. Dis., 4, $1154-1160$

19.Van Doorn H.R., Hofwegen H., Koelewijn R., Gilis H., Peek R., Welsteyn J.C., Van Genderen P.J., Vervoort T., Van Gool T. (2005). Use of rapid dipstick and latex agglutination tests and enzyme-linked immunosorbent assay for serodiagnosis of amebic liver abscess, amebic colitis and Entamoeba histolytica cyst passer. J. Clin. Microbiol., 43(9), 4801-4806.

20.Van Hal, S. J., Stark, D. J., Fotedar, R., Marriott, D., Ellis, J. T., \& Harkness, J. L. (2007). Amoebiasis: current status in Australia. Medical journal of Australia, 186(8), 412.

21.Walsh J.A. (1986)-Problems in recognition and diagnosis of amoebiasis: estimation of the global magnitude of morbidity and mortality. Rev. Infec. Dis., 8, 228

22.Wong et al., (2017) also have done similar type of work using crude soluble antigen of $E$. histolytica

23. Yamura H., Araki K., Kikuchi K., Itoda I., Totsuka K., Kobayakawa T. (2003), Evaluation of dot-ELISA for serological diagnosis of amoebiasis. J. Infect. Chemother., 9(1), 25-29. 